\title{
Minimally Invasive Mitral Valve Surgery I Patient Selection, Evaluation, and Planning
}

Gorav Ailawadi, MD, * Arvind K. Agnihotri, MD, † John R. Mehall, MD, $\neq$. Alan Wolfe, MD, $\S$

Brian W. Hummel, MD,// Trevor M. Fayers, FRACS, 9 R. Saeid Farivar, MD, PhD,\# Eugene A. Grossi, MD, **

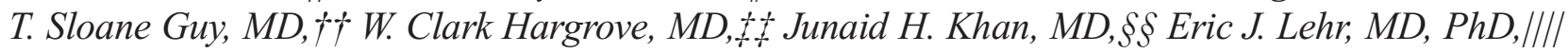

S. Chris Malaisrie, MD, $\$$ \ Douglas A. Murphy, MD, \#\# Evelio Rodriguez, MD, *** William H. Ryan, MD, †† Arash Salemi, MD, +f Romualdo J. Segurola Jr, MD, $\$ \oint$ Richard J. Shemin, MD, ///// J. Michael Smith, MD, 999

Robert L. Smith, MD, †† Paul W. Weldner, MD,\#\#\# Scott M. Goldman, MD, ****

Clifton T. P. Lewis, MD, ††† and Glenn R. Barnhart, MD///

\begin{abstract}
Widespread adoption of minimally invasive mitral valve repair and replacement may be fostered by practice consensus and standardization. This expert opinion, first of a 3-part series, outlines current best practices in patient evaluation and selection for minimally invasive mitral valve procedures, and discusses preoperative planning for cannulation and myocardial protection.
\end{abstract}

Accepted for publication June 16, 2016.

From the *University of Virginia, Charlottesville, VA USA; $†$ Saint Elizabeth's Medical Center, Brighton, MA USA; †Penrose St. Francis Hospital, Colorado Springs, CO USA; §Northeast Georgia Physicians Group, Gainesville, GA USA; ||Gulf Coast Cardiothoracic and Vascular Surgeons, Ft. Myers, FL USA; $₫$ Holy Spirit Northside Hospital, Chermside, Australia; \#Minneapolis Heart Institute, Abbott Northwestern Hospital, Minneapolis, MN USA; **New York University School of Medicine, New York, NY USA; ††Temple University, Philadelphia, PA USA; \$\$Penn Presbyterian Medical Center, Philadelphia, PA USA; §§East Bay Cardiac Surgery Center, Oakland, CA USA; ||||Swedish Heart and Vascular Institute, Seattle, WA USA; qINorthwestern University, Feinberg School of Medicine, Chicago, IL USA; \#\#Emory St. Joseph's Hospital, Atlanta, GA USA; ***St. Thomas Hospital, Nashville, TN USA; ††The Heart Hospital Baylor Plano, Plano, TX USA; t+ttWeill Cornell Medical College/New York Presbyterian Hospital, New York, NY USA; $\S \S S o u t h$ Florida Heart \& Lung Institute, Doral, FL USA; ||||||David Geffen School of Medicine, University of California Los Angeles, Los Angeles, CA USA; $\mathbf{q \uparrow \uparrow T r i H e a l t h ~}$ Heart Institute, Cincinnati, OH USA; \#\#\#Central Maine Heart and Vascular Institute, Lewiston, ME USA; **** Lankenau Medical Center, Wynnewood, PA USA; and $\uparrow \dagger \dagger$ Department of Cardiothoracic Surgery, Princeton Baptist Hospital, Birmingham, AL USA.

Supported by Princeton Baptist Hospital, Birmingham, AL USA, which provided funds for medical editing assistance, which was performed by Jeanne McAdara-Berkowitz, PhD. The funds came from an educational budget and were not provided by any commercial entity. Medical illustrations created by Jill Rhead, MA, CMI, FAMI were donated by Edwards Lifesciences Corp, Irvine, CA USA.

Disclosures: See next page.

Address correspondence and reprint requests to Glenn R. Barnhart, MD, Swedish Heart and Vascular Institute, 1600 E. Jefferson, Suite 110, Seattle, WA 98122 USA. E-mail: glenn.barnhart@swedish.org.

Copyright (c) 2016 by the International Society for Minimally Invasive Cardiothoracic Surgery

This is an open-access article distributed under the terms of the Creative Commons Attribution-Non Commercial-No Derivatives License 4.0 (CCBY-NC-ND), where it is permissible to download and share the work provided it is properly cited. The work cannot be changed in any way or used commercially.

ISSN: $1556-9845 / 16 / 1104-0243$
Key Words: Minimally invasive surgery (includes port access, minithoracotomy), Mitral valve, repair, replacement, Surgery/incisions/ exposure/techniques, MVR, MIMVR, Heart valve.

(Innovations 2016;11: 243-250)

Datients' demand for minimally invasive cardiac procedures has risen dramatically since the Heartport platform was first developed in $1996 .{ }^{1}$ Although early outcomes in coronary artery bypass grafting with this platform were less than desirable owing to steep learning curves,${ }^{1-3}$ use of minimally invasive approaches for valve surgery has increased. ${ }^{4-10}$ Today, minimally invasive approaches to mitral valve repair and replacement (MIMVR) have become preferred at numerous centers owing to less postoperative bleeding and atrial fibrillation, a reduced incidence of wound infection, and shorter hospital stays, quicker recovery, and improved cosmesis. ${ }^{11-16}$ Nevertheless, MIMVR's benefits are not accepted universally, and many surgeons remain apprehensive about developing a MIMVR program owing to learning curves and potential complications.

\section{See accompanying editorial on page 233, and articles on pages 251 and 260}

Recognizing this knowledge and practice gap, a group of 26 experienced MIMVR surgeons convened to develop consensus guidance aimed at facilitating adoption of MIMVR. This report is the collaborative effort of these surgeons who collectively have performed approximately 17,000 MIMVR procedures. This work is the first of a 3-part series and details considerations for patient evaluation and selection, as well as preoperative planning for successful cannulation, systemic perfusion, myocardial protection, and anesthetic preparation. The second report focuses on intraoperative techniques to perform MIMVR while minimizing complications, ${ }^{17}$ and the third manuscript describes considerations specific to robotic-assisted MIMVR, as well as training pathways that will prepare a surgical team to move from sternotomy to port access to robotic approaches. ${ }^{18}$

The recommendations in these 3 reports are presented to provide a framework to the new user of MIMVR. They are based on the 4 fundamental tenets of any cardiac operation including: 
Disclosures: All authors declare that they serve as consultants on the Medical Advisory Board for Edwards Lifesciences Corp, Irvine, CA USA. In addition, Gorav Ailawadi, MD, is a consultant to Abbott Vascular, Abbott Park, IL USA, AtriCure, Inc, West Chester, OH USA, Medtronic, Inc, Minneapolis, MN USA, and St. Jude Medical, Inc, St. Paul, MN USA. John R. Mehall, MD, is a consultant to AtriCure, Inc, West Chester, OH USA. Brian W. Hummel, $\mathrm{MD}$, is a consultant to AtriCure, Inc, West Chester, OH USA, and Medtronic, Inc, Minneapolis, MN USA. R. Saeid Farivar, MD, PhD, is a consultant to Abbott Vascular, Abbott Park, IL USA, and Medtronic, Inc, Minneapolis, MN USA. Eugene A. Grossi, MD, is a consultant to Medtronic, Inc, Minneapolis, MN USA, and Intuitive Surgical, Sunnyvale, CA USA. T. Sloane Guy, MD, is a consultant to Medtronic Inc, Minneapolis, MN USA, and Ethicon Inc/Johnson\&Johnson, Somerville, NJ USA, and a recipient of a grant from Biomet, Inc, Warsaw, IN USA. W. Clark Hargrove, MD, was a consultant to Sorin/LivaNova, Milan, Italy. S. Chris Malaisrie, MD, is a consultant for Medtronic, Inc, Minneapolis, MN USA, and Abbott Vascular, Abbott Park, IL USA. Douglas A. Murphy, MD, receives product royalties from Medtronic, Inc, Minneapolis, MN USA. Evelio Rodriguez, MD, is a consultant to Abbott Vascular, Abbott Park, IL USA, AtriCure, Inc, West Chester, OH USA, and St. Jude Medical, Inc, St. Paul, MN USA, is a grant recipient from Medtronic, Inc, Minneapolis, MN USA, and serves on the speaker's bureaus for Edwards Lifesciences, Corp, Irvine, CA USA, and Medtronic, Inc, Minneapolis, MN USA. William H. Ryan, MD, is a consultant to Medtronic, Inc, Minneapolis, MN USA. Arash Salemi, MD, is a consultant to Medtronic, Inc, Minneapolis, MN USA. J. Michael Smith, MD, is a consultant to AtriCure, Inc, West Chester, OH USA, and Intuitive Surgical, Sunnyvale, CA USA. Robert L. Smith, MD, serves on the speaker's bureaus for Abbott Vascular, Abbott Park, IL USA, and Intuitive Surgical, Inc, Sunnyvale, CA USA. Scott M. Goldman, MD, serves on advisory boards for Abbott Vascular, Abbott Park, IL USA, and Medtronic, Inc, Minneapolis, MN USA, and is a consultant to St. Jude, Inc, St. Paul, MN USA, and LSI SOLUTIONS, Victor, NY USA. Clifton T. P. Lewis, MD, is a consultant to Intuitive Surgical, Inc, Sunnyvale, CA USA. Glenn R. Barnhart, MD, is a consultant to AtriCure, Inc, West Chester, OH USA, and On-X Life Technologies, Austin, TX USA. Arvind K. Agnihotri, MD, J. Alan Wolfe, MD, Trevor M. Fayers, MD, Junaid H. Khan, MD, Eric J. Lehr, MD, PhD, Romualdo J. Segurola, Jr, MD, Richard J. Shemin, MD, and Paul W. Weldner, MD, declare no other conflicts of interest.

(1) establishment and maintenance of adequate cannulation and perfusion, (2) complete myocardial protection, (3) optimal exposure, and (4) procedures appropriate to the patient's specific pathology. ${ }^{19}$ As in conventional mitral valve surgery, none of these tenets should ever be compromised when considering less invasive approaches.

\section{PATIENT SCREENING}

When starting an MIMVR program, all patients with isolated MV disease should be considered candidates for MIMVR until proven otherwise. There are, however, a number of comorbidities and anatomical considerations that should be viewed as relative contraindications (Table 1). With increasing surgical MIMVR experience, select patients with these high-risk comorbidities may be considered as well. Ultimately, the goal is to provide a safe, reliable, and reproducible operation with similar or better outcomes than with median sternotomy. Evaluation of

\section{TABLE 1. Relative Contraindications to MIMVR}

Significant aortic, iliac, or femoral disease that prevents safe retrograde arterial perfusion

Left ventricular ejection fraction $<25 \%$

Severe right ventricular dysfunction

Pulmonary artery pressure $>70 \mathrm{~mm} \mathrm{Hg}$

Aorta $>4 \mathrm{~cm}$ if endoaortic balloon being used

Significant mitral annular calcification

Patients with more than mild aortic regurgitation

Kyphoscoliosis and pectus excavatum

Morbidly obese and extremely muscular patients
TABLE 2. Comorbidities of Concern for MIMVR Patient Selection

\begin{tabular}{ll}
\hline Comorbidity & \multicolumn{1}{c}{ Potential Complication } \\
\hline Morbid obesity & Compromised exposure \\
Significant lung disease & Postoperative respiratory failure \\
Peripheral vascular disease & Malperfusion and possible arterial injury \\
Advanced renal dysfunction & Postoperative renal failure \\
Advanced liver disease & Postoperative hepatic failure \\
Previous right thoracotomy & Compromised exposure; lung injury \\
Significant pulmonary hypertension & Inadequate postoperative RV function \\
Severe LV dysfunction & Inadequate postoperative LV function \\
\hline
\end{tabular}

potential patients for MIMVR should include careful history for relevant comorbidities, examination for body habitus, and a series of screening tests including computed tomography (CT) angiography, echocardiography, as well as pulmonary function testing and cardiac catheterization or coronary CT when indicated.

The ideal patient to begin MIMVR is one who requires an isolated MV procedure (repair or replacement). Once a surgeon gains experience, concurrent procedures such as tricuspid valve or Maze procedures can also be performed through a port-access incision. Hybrid approaches with percutaneous coronary intervention and port-access MV surgery may be an option for select patients, but pose additional considerations such as the order in which the 2 procedures would be performed and initiation and cessation of platelet inhibitors.

\section{Comorbidities}

The presence of some comorbidities makes certain patients less-than-ideal candidates for MIMVR for different reasons (Table 2), especially in a program's early experience when cardiopulmonary bypass (CPB) times will likely trend longer.

Age itself should not be considered a contraindication, as elderly, frail patients may benefit most from MIMVR approaches. Patients with previous stroke and difficulty with mobility may also derive significant benefit from avoiding sternotomy. Careful assessment of vasculature should be undertaken in both of these populations, since they often have higher calcium burden.

\section{Physical Examination and Body Habitus}

The regional anatomy of the right chest and overall body habitus must be evaluated (Table 3 ). One should examine the right chest to determine whether the rib intercostal spaces are palpable, and chest CT is helpful in assessing both body

TABLE 3. Anatomic Considerations for MIMVR Patient Selection

\begin{tabular}{ll}
\hline Anatomic Feature & \multicolumn{1}{c}{ Considerations } \\
\hline $\begin{array}{l}\text { Heart } \\
\begin{array}{l}\text { Aortic root, } \\
\text { ascending } \\
\text { aorta, and arch }\end{array}\end{array}$ & $\begin{array}{l}\text { Size and location } \\
\text { Anatomy and extent of calcification; aneurysm; } \\
\text { dissection; diameter for occlusion approaches }\end{array}$ \\
Chest annulus & $\begin{array}{l}\text { Calcification } \\
\text { Distance to MV; obesity; muscularity; pectus excavatum; } \\
\text { prior rib fracture; high right diaphragm; scoliosis; } \\
\text { presence and location of breast implants }\end{array}$ \\
Lungs & $\begin{array}{l}\text { Location of the pulmonary hilum in relation to planned } \\
\text { working incision }\end{array}$
\end{tabular}


fat distribution and muscularity. Significantly, obese or muscular patients with thick chest walls can be challenging owing to the added distance to the MV. Extremely muscular soft tissues are difficult to compress, making exposure through the rightchest working port challenging.

There are several considerations for female patients. During examination, consideration should be given to the location and extent of the incisions relative to the breast. The incisions can be made at the inframammary fold or lateral to the breast to avoid subsequent bra irritation. Women with breast implants should be assessed preoperatively to ensure that the appropriate intercostal space for the working port can be used, that the leftatrial roof retraction post can be placed medially without damaging the implant, and to identify compromised implant integrity. In certain cases, the implant may be removed and then replaced after the MVR is performed. At the time of operation, the right breast should be retracted toward the left shoulder and held in place with an adhesive sterile plastic drape.

Patients with prior chest trauma, chest tubes, history of pneumothorax, or surgery to the right chest typically have adhesions that can add time and morbidity to the operation. The surgeon must weigh the benefit of MIMVR against the risk of added operative time and potential for pulmonary injury. In such cases, it may be prudent to perform a thoracoscopy through a 5 -mm camera port to determine if a right chest approach is safe. If dense adhesions are encountered, another route is advisable.

Anatomic considerations include patients with kyphoscoliosis or pectus excavatum, which can compromise exposure. In these deformities, cardiac migration into the left chest occurs, limiting working angles between the sternum and the spine and making exposure difficult. This results in limited ability to lift the atrial septum and creates additional distance between the incision and the heart.

Finally, if contemplating femoral cannulation, the surgeon should evaluate the groins for suitable access, including palpable arterial pulses, evidence of inguinal or femoral hernia (or history of repaired hernia), large pannus, or concern for fungal infiltration of the groin.

\section{Echocardiography}

Thorough assessment of MV and other cardiac pathologies is necessary for safe patient selection (Table 4). A high-quality transthoracic echocardiogram may diagnose the mechanism of MV disease, but if it remains unclear, a preoperative

TABLE 4. Important Echocardiographic Findings During MIMVR Patient Selection

\begin{tabular}{|c|c|}
\hline Location & Notable Echocardiographic Findings \\
\hline Mitral valve & $\begin{array}{l}\text { Lesions and etiology of MV disease; risk factors for systolic } \\
\text { anterior motion; extent of annular calcification; presence } \\
\text { of rheumatic disease }\end{array}$ \\
\hline Tricuspid valve & Insufficiency; stenosis \\
\hline Aortic valve & Insufficiency; stenosis \\
\hline $\begin{array}{l}\text { Left and right } \\
\text { ventricles }\end{array}$ & End diastolic dimensions, ejection fraction $<25 \%$ \\
\hline Pulmonary artery & Pulmonary hypertension (systolic pressures > 70 mm Hg) \\
\hline Coronary sinus & Enlargement may be associated with a persistent left SVC \\
\hline Aorta & Atheroma \\
\hline
\end{tabular}

transesophageal echocardiogram (TEE) is warranted..$^{20}$ Ideal initial cases for MIMVR include patients who require a simple annuloplasty, a focal posterior leaflet prolapse, or MV replacement.

Mitral valve pathologies that are less amenable to port-access MV surgery include significant mitral annular calcification in which extensive debridement may be necessary, or those that require extremely complex repair (eg, for rheumatic MV disease). Mitral annular calcification significantly increases the risk of atrioventricular disruption, and annular decalcification and subsequent suture placement can be difficult with singleshaft instruments. Thus, preventive complex repair techniques may need to be used to prevent this lethal complication. In these most complicated MV operations, the surgeon's experience should dictate the approach.

Patients with more than mild aortic valve insufficiency should be approached with caution through the right chest, as arresting, protecting, and decompressing the heart may be challenging. Greater consideration should be given to placing a retrograde cardioplegia cannula, either directly through the right atrium or through the right internal jugular (IJ) vein.

Since ischemic times are usually longer in right chest approaches, caution is advised in patients with an extremely low left ventricular (LV) ejection fraction $(<25 \%)$; particularly if there is any concern that temporary left ventricular assist device support may be required postoperatively. Patients with significant right ventricular (RV) dysfunction or systolic pulmonary artery pressures greater than $70 \mathrm{~mm} \mathrm{Hg}$ are known to have a higher risk of mortality with surgery despite their STS risk. ${ }^{21}$ There is a concern that the RV is not as well protected in the right chest approach since the RV cannot be topically cooled, although this can be mitigated by using lower systemic perfusate temperatures and more frequent redosing of cardioplegia. In any MIMVR candidate with RV dysfunction or severe pulmonary hypertension, optimal venous drainage is of even more importance to preserve RV function upon separation from CPB.

Finally, echocardiography should be used to assess aortic atheroma in conjunction with the chest $\mathrm{CT}$, as significant atheroma increases stroke risk and MIMVR is not ideal in this setting.

\section{Computed Tomographic Imaging of the Chest}

In recent years, CT angiography (CTA) has become routine in evaluating patients for minimally invasive valve surgery. ${ }^{19}$ There are a number of factors to evaluate on the chest CT (Table 5). Since aortic occlusion is accomplished with either an external cross-clamp or an internal endoaortic balloon, ascending aortic disease must be ruled out by CT. Complete occlusion with the endoaortic balloon becomes less consistent in aortas greater than $4 \mathrm{~cm}$ in diameter. Computed tomography is also necessary to detect significant MV annular calcification, which is a relative contraindication for MIMVR for inexperienced surgeons.

The fourth intercostal space is most commonly used for the working port; however, CT may help guide the surgeon above or below this space to be in line with the pulmonary hilum. Other anatomic abnormalities such as deformations in the chest wall, ribs, or diaphragm should be evaluated for their potential to complicate the surgical approach. 
TABLE 5. Useful CTA Findings During MIMVR Patient Evaluation

\begin{tabular}{lc}
\hline Finding & Considerations \\
\hline Aorta & $\begin{array}{c}\text { Evaluate degree, location, and type of atheroma, including hard vs soft plaque; measure diameter of ascending } \\
\text { aorta (must be }<4 \mathrm{~cm} \text { for endoaortic balloon) } \\
\text { Rule out aberrant anatomy, including patent ductus arteriosus, persistent left SVC, and } \\
\text { aberrant right subclavian artery, which may make monitoring of an endoaortic balloon difficult } \\
\text { Evaluate degree of mitral annular calcification }\end{array}$ \\
$\begin{array}{ll}\text { Mitral valve } \\
\text { Iliac artery }\end{array}$ \\
$\begin{array}{ll}\text { Rommon femoral and superficial femoral artery } \\
\text { Venous anatomy }\end{array}$ & $\begin{array}{l}\text { Identify bifurcation and location for site choice; measure common femoral artery diameter for cannulation } \\
\text { Rule out venous anomalies or IVC filter }\end{array}$ \\
\hline
\end{tabular}

\section{CT Imaging of the Aortoiliofemoral Vasculature}

Although MIMVR can be performed with central cannulation techniques, most surgeons prefer peripheral cannulation to minimize the chest incision and rib spreading, and to provide uncluttered access to the MV. Planning for this approach requires thorough knowledge of the peripheral vascular anatomy.

Computed tomographic angiography (CTA) of the chest, abdomen, and pelvis, preferably with contrast, provides the most useful anatomic information. Computed tomographic without contrast is still helpful but may not reveal subtleties in soft plaque, an important consideration for peripheral cannulation and retrograde arterial perfusion. The femoral and iliac arteries and aorta should have minimal calcium, thrombus, or aneurysmal disease when planning femoral arterial access. Evidence of an iliac or femoral artery dissection is a contraindication for ipsilateral peripheral arterial cannulation. Patients with a history of peripheral vascular disease should undergo evaluation with lower extremity noninvasive studies and/or lower extremity CTA, as cannulation can result in lower-extremity ischemia while on $\mathrm{CPB}$.

The venous anatomy should also be assessed. Although it is unusual that femoral venous access cannot be used, patients with a history of deep vein thrombosis, and particularly those with an inferior vena cava (IVC) filter, may require a CT venogram to ensure the IVC is patent.

\section{Other Preoperative Testing}

American Heart Association guidelines for left heart catheterization include male patients older than 40 and postmenopausal women undergoing valvular surgery. ${ }^{20}$ Radial artery access for cardiac catheterization is preferred to preserve a virgin operative field and avoid local dissection of the femoral arteries before port-access surgery. In patients who have a low likelihood of disease or in young patients, one should consider coronary CTA. Other conventional tests include carotid artery duplex scan and pulmonary function testing as necessary. In young patients, assessment of the coronary artery is not necessary but can still be helpful to assess dominance and ability to protect the RV as well as the proximity and size of the circumflex artery relative to the MV annulus. In cases with significant LV or RV dysfunction, or significantly elevated pulmonary artery pressures are suggested by echocardiogram, consideration for catheterization of the right side of the heart should be given.

\section{ANESTHESIA AND MONITORING}

Although the principles and conduct of the operation have similarities to a sternal approach, there is a greater reliance on perfusion and anesthesia to perform MIMVR. When using a transthoracic cross-clamp, a radial arterial line is often sufficient. However, when using an endoaortic balloon, bilateral radial or brachial arterial monitoring is necessary to ensure proper positioning of the device in the ascending aorta. Alternatives also include use of right radial and femoral arterial monitoring.

Since access to the MV is through the right chest, a double lumen endotracheal tube (or a single lumen with bronchial blocker for an experienced anesthesiologist) is preferable, as it is not uncommon to inflate and deflate the right lung while de-airing and assessing for bleeding after CPB. This is especially true early in one's experience.

After insertion of the TEE, a thorough inspection of the MV and for any concomitant disease should be performed before proceeding with MIMVR. One concern that has limited adoption of MIMVR for many programs is the challenge of placing a retrograde cardioplegia cannula into the coronary sinus. As previously noted, there are several options including avoidance of its use, placement directly through the working port, or preoperative transjugular coronary sinus cannulation. In the latter scenario, the anesthesiologist places the cannula at the time of central line insertion through the right IJ vein into the coronary sinus with echocardiographic and fluoroscopic guidance. In addition, a pulmonary artery vent can be placed percutaneously, which can monitor the pulmonary artery pressures and function as a vent.

Other adjuncts to consider include cerebral and lower extremity oximetry to aid in identification of hypoperfusion to the brain and in diagnosis of leg ischemia from peripheral cannulation, respectively. ${ }^{22}$ Monitoring of the lower extremities with near-infrared oximetry can allow for instantaneous comparisons of blood flow between the cannulated and non-cannulated extremity. If comparison to the contralateral leg shows a significant difference, a small cannula should be placed in the distal superficial femoral artery to avoid leg ischemia. ${ }^{17}$

\section{CANNULATION AND PERFUSION CONSIDERATIONS}

Because MIMVR affords less ability to visualize the whole heart, a well thought out plan for cannulation, perfusion, and myocardial protection should be made before going to the operating room (Fig. 1). The goals of cannulation and perfusion are to (1) provide complete drainage to the heart, (2) provide 


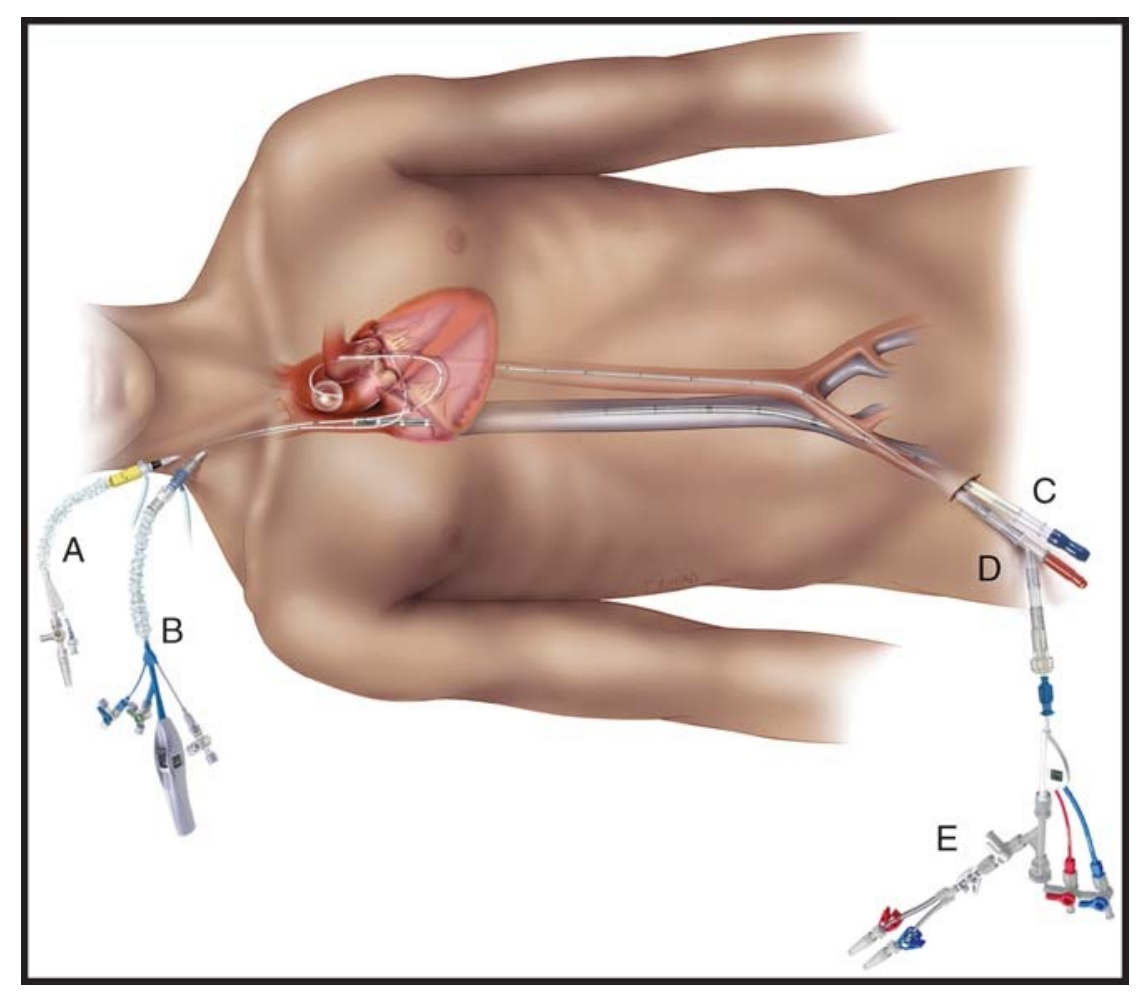

FIGURE 1. Placement of perfusion catheters and cannulas in minimally invasive mitral valve repair and replacement. A, Pulmonary artery vent catheter. B, Coronary sinus catheter. C, Femoral venous cannula. D, Femoral arterial cannula. E, Endoaortic balloon occlusion catheter.

adequate systemic perfusion, (3) minimize risks of malperfusion or vascular injury, and (4) minimize added time and cost.

\section{Arterial Cannulation}

As previously noted, CTA is essential in choosing arterial access. Arterial perfusion for minimally invasive cardiac surgery is generally done via the larger, less diseased common femoral artery. The adequacy of femoral artery size can be anticipated by CTA measurement. A 23-F side-arm arterial cannula should be used if the femoral artery size will allow; if a 21-F side-arm cannula is used, a higher arterial line pressure should be anticipated. If the femoral arteries are too small to accommodate a $21 \mathrm{~F}$ and if an endoaortic balloon is to be used, then a 19-F cannula can be placed in each femoral artery for perfusion and for the endoaortic balloon; alternatively, to avoid bilateral femoral artery cannulation, the transthoracic aortic cross-clamp can be used. In situations where the vessel is not diseased but is small, a graft can be sewn on the femoral artery in an end-to-side fashion and cannulated to minimize risk of lower-extremity ischemia. In all circumstances, CPB should be initiated slowly to prevent arterial spasm. The descending thoracic aorta should be visualized by TEE as cardiopulmonary bypass is initiated in the rare likelihood a false lumen is being created.

When the femoral system is not suitable for arterial inflow, right or left axillary artery cannulation can be performed. Some surgeons prefer central arterial cannulation as one report has suggested a higher stroke rate with femoral cannulation, ${ }^{23}$ although arterial cannulas can be challenging to insert or cannulation sites difficult to repair through small incisions. Exposure of the ascending aorta for cannulation can be performed through the working port or may require an additional incision, usually right parasternal in the second or third intercostal space. This can either be combined with direct clamping or with a specialized cannula with balloon occlusion capabilities.

\section{Venous Cannulation}

Without adequate venous drainage, MIMVR becomes significantly more challenging. Visualization can be difficult with greater left heart return, and myocardial protection is less than optimal. Venous drainage routinely uses a multistage femoral venous catheter, typically placed from the right femoral vein with advancement and final positioning in the superior vena cava (SVC) under TEE guidance. The right femoral vein is generally preferred over the left owing to the more favorable relationship with the iliac artery, where compression from that structure on the left may impede passage. In patients with an IVC filter, the femoral venous cannula can be passed through the filter, but this may require fluoroscopic guidance. An alternative is to advance the femoral venous cannula to the filter and percutaneously place a $15-\mathrm{F}$ to $18-\mathrm{F}$ femoral arterial cannula through the IJ vein into the SVC.

Some centers routinely place a second venous line $(15 \mathrm{~F}$ to $18 \mathrm{~F}$ ) positioned into the SVC to aid in venous drainage. This can be done from a low right jugular approach and completed either by the anesthesiology team or by the surgeon using a small previously placed catheter that has been prepped into the surgical field. In this case, the femoral venous cannula would only be advanced to the IVC right atrial junction. In patients 
undergoing transthoracic cross-clamping, rarely a patient will need bicaval cannulation in situations where venous drainage is inadequate with a single femoral venous cannula or exposure of the valve is compromised. Two venous lines may alleviate concern about affecting drainage caused by left atrial retraction, but a single venous cannula with correct placement and vacuum assistance is often sufficient. Another adjunct that can help with drainage is the use of the percutaneous pulmonary arterial (PA) vent. This can be placed through the right jugular vein by the anesthesiologist.

In all cases, consideration should be given to patient size when deciding on single or double venous cannulation as well as the use of a pulmonary artery vent. The surgeon must be flexible during the conduct of the operation to achieve the end goal of adequate drainage, and must be willing to place a second venous line to achieve this goal, either through the SVC or through the right atrium proper.

\section{MYOCARDIAL PROTECTION AND AORTIC OCCLUSION}

Since most MIMVR procedures are done with peripheral cannulation, the strategies for myocardial protection and aortic occlusion are different from those of sternotomy, although the goals remain the same (Table 6).

\section{Ventricular Fibrillation}

The simplest option for myocardial protection is to avoid aortic occlusion and cardioplegic arrest by using either ventricular fibrillation or a beating heart strategy. The technique of ventricular fibrillation for MV surgery presents potential disadvantages; and therefore, many MIMVR surgeons do not use ventricular fibrillation as their standard myocardial protection strategy for most cases. A large series has suggested a higher perioperative stroke rate compared to aortic occlusion and cardioplegic arrest. ${ }^{24}$ Higher stroke rates may be due to a number of factors, including the common practice of using "pumpoff" periods to place anterior sutures; or to entraining air into the LV with no ability to capture any air that is pushed into the ascending aorta. Although this may be mitigated by the routine use of $\mathrm{CO}_{2}$ in the chest, inadequate de-airing may explain worse outcomes with this approach. Moreover, ventricular fibrillation cannot be used if there is any appreciable degree of aortic insufficiency, which obscures the surgical field with blood. Finally, atrial retraction may render the aortic valve incompetent and result in excessive aortic insufficiency with blood return into the LV; this can be especially challenging when trying to place sutures in the left trigone. There are certain settings such as previous cardiac surgery with patent grafts or previous aortic valve replacement in which ventricular fibrillation may be preferred, ${ }^{25,26}$ and the principles and strategies of this technique should be appreciated by the MIMVR surgeon; however, it is not recommended by these authors as a standard choice for MIMVR surgery.

\section{Cardioplegia-Based Strategies}

When using cardioplegia, the surgical team should preoperatively plan an antegrade approach alone or a combined antegrade and retrograde approach. This strategy can mirror the team's customary approach and comfort level during conventional sternotomy approaches to MV surgery. Although limited, growing experience with del Nido cardioplegia or crystalloid histidine-tryptophan-ketoglutarate cardioplegia solutions suggest that they require less frequent dosing and may reduce the need for placement of retrograde cardioplegia. Any degree greater than mild aortic valve regurgitation should prompt a consideration for the use of retrograde cardioplegia.

Antegrade cardioplegia can be delivered by 2 approaches. The first is by way of the aortic root through an externally inserted cardioplegia needle. This is typically brought out through the working port but can be placed through a separate small incision in the right chest. In this scenario, a transthoracic cross-clamp is required. The alternative is to use an endoaortic balloon to occlude the aorta internally. With this technique, antegrade cardioplegia is delivered through the endoaortic balloon to the aortic root. If the endoaortic balloon is used for antegrade cardioplegia delivery, higher line pressures and longer infusion times should be anticipated given the length of the catheter. The use of an endoaortic balloon requires additional skill of the surgical team, including the perfusionist.

If retrograde cardioplegia is planned, there are 2 main options for insertion. One is through the right atrium into the coronary sinus; the other uses percutaneous coronary sinus

TABLE 6. Comparison of Transthoracic Cross-Clamping, Endoaortic Balloon Occlusion, and Ventricular Fibrillation

\begin{tabular}{|c|c|c|c|}
\hline Consideration & Transthoracic Cross-Clamping & Endoaortic Balloon & Ventricular Fibrillation \\
\hline Effective aortic occlusion & Always & May migrate to arch vessels & No occlusion \\
\hline $\begin{array}{l}\text { Operative field encroachment and venous } \\
\text { drainage impairment }\end{array}$ & Occasional & None & None \\
\hline Mitral valve exposure & Optimal & Optimal & $\begin{array}{l}\text { Suboptimal; especially with } \\
\text { aortic regurgitation }\end{array}$ \\
\hline Risk of aortic injury & Possible adventitial hematoma & Possible aortic dissection (?) & None \\
\hline De-airing and stroke & Adequate de-airing & Adequate de-airing & $\begin{array}{l}\text { Increased risk for air embolism } \\
\text { and stroke }\end{array}$ \\
\hline Surgeon learning curve & Moderate & Increased & Short \\
\hline Cost & + & +++ & None \\
\hline
\end{tabular}


cannulation through the right IJ vein (see section on "Anesthesia and Monitoring").

\section{Aortic Occlusion}

Aortic occlusion can be achieved with a transthoracic cross-clamp or through endoaortic balloon occlusion. Early in experience, most MIMVR surgeons begin with transthoracic cross-clamping, as this is a familiar technique that allows direct clamping of the aorta as one would typically do through a sternotomy. The clamps are reusable and reproducible, and the technique is inexpensive to use. The transthoracic cross-clamp is placed through an entry site in the chest wall, anterior to the SVC. There is potential for obstruction of upper-body venous drainage from the cross-clamp, but this can be avoided by either bicaval cannulation or proper position of a single venous femoral cannula above the site where the cross-clamp crosses anterior to the SVC.

The alternative to the transthoracic cross-clamp is endoaortic balloon occlusion. Advantages of this technique include the absence of a cardioplegia hole in the ascending aorta and its potential problems. Because cardioplegia delivery and root venting are performed through the catheter itself, there is no need for a separate antegrade cardioplegia root catheter. This eliminates any issues with suturing the aorta or bleeding from the puncture site, and minimizes clutter in the operative field. Other advantages are that it is inserted into the ascending aorta before initiating CPB and can actually shorten pump and clamp times. It is also ideal for use in redo operations.

Disadvantages of endoaortic balloon occlusion include the need to place the catheter through the arterial cannula, hence reducing the effective size of the arterial cannula. If this results in excessively high line pressures or inadequate flow, then the option exists to place the balloon through a separate arterial cannulation site. Distal balloon migration resulting in innominate artery occlusion has been observed, as has proximal migration with the potential to obscure the operative field, especially the left fibrous trigone. Distal balloon migration can be easily recognized by monitoring bilateral radial artery pressures, and the potential for migration can be mitigated by proper positioning. Early use of the endoaortic balloon raised concerns of its association with aortic dissection, but this occurred in an era before routine CTA use and awareness of the importance of imagining when considering retrograde arterial perfusion. Other disadvantages include the cost of the catheter itself, the need for bilateral arterial lines to monitor placement, and possible balloon puncture or rupture during the procedure.

There are limited and exclusively retrospective data comparing transthoracic cross-clamping and endoaortic balloon occlusion. From the available data, there is no significant difference in safety profiles between the 2 techniques. Both techniques have a significantly lower stroke rate than ventricular fibrillation. There is no difference in retrograde aortic dissection, bleeding, or adequacy of myocardial protection. ${ }^{24,27,28}$

\section{DISCUSSION AND CONCLUSION}

It is noteworthy that the International Society for Minimally Invasive Cardiothoracic Surgery (ISMICS) published a consensus statement in 2010 that listed the following limitations to MIMVR versus open mitral repair: increased risk of stroke, increased risk of aortic dissection, phrenic nerve palsy, groin complications, and prolonged cross-clamp times. ${ }^{11}$ As noted in the statement, the data upon which these observations were made are almost entirely based on observational studies and not randomized prospective studies. It remains true today that there are no randomized prospective studies to definitively address these issues. The ISMICS statement was based on literature published before March 2010 and, by their own statement, included only "retrospective studies with important differences in baseline patient characteristics." However, a few observations can be made. Use of CTA for preoperative planning was used only uncommonly by most MIMVR surgeons in the period before 2010. This might explain the observed increased incidence of stroke and aortic dissection; the authors went into great detail concerning the use of CTA for preoperative planning to avoid these complications. Most MIMVR surgeons today are well aware of the possibility of phrenic nerve palsy and have taken steps to avoid its occurrence. With increasing experience, groin complications (lymphocele, arterial complications, infection) have become exceedingly rare. Whereas MIMVR increases cross-clamp time, the ISMICS consensus statement did not show an increased mortality when compared to open mitral repair.

In summary, selection of ideal patients and a welldeveloped preoperative plan involving the operating room team, the anesthesiologists, perfusionists, and surgeons are necessary to a successful MIMVR program. It is imperative that the team is comfortable with conventional MV surgery, including techniques for repair through a sternotomy, before embarking on MIMVR; and all team members must have a thorough understanding of the procedure, its potential pitfalls, and complications. If the 4 inviolate principles of safe and reproducible cardiac surgery as described in this paper are rigorously adhered to, then the chances of program success will be greatly increased.

\section{REFERENCES}

1. Stevens JH, Burdon TA, Peters WS, et al. Port-access coronary artery bypass grafting: a proposed surgical method. J Thorac Cardiovasc Surg. 1996;111:567-573

2. Groh MA, Sutherland SE, Burton III HG, Johnson AM, Ely SW. Port-access coronary artery bypass grafting: technique and comparative results. Ann Thorac Surg. 1999;68:1506-1508.

3. Grossi EA, Groh MA, Lefrak EA, et al. Results of a prospective multicenter study on port-access coronary bypass grafting. Ann Thorac Surg. 1999;68:1475-1477.

4. Cohn III LH, Adams DH, Couper GS, et al. Minimally invasive cardiac valve surgery improves patient satisfaction while reducing costs of cardiac valve replacement and repair. Ann Surg. 1997;226:421-427.

5. Cosgrove III DM, Sabik JF, Navia JL. Minimally invasive valve operations. Ann Thorac Surg. 1998;65:1535-1538.

6. Falk V, Walther T, Diegeler A, et al. Echocardiographic monitoring of minimally invasive mitral valve surgery using an endoaortic clamp. J Heart Valve Dis. 1996;5:630-637.

7. Glower DD, Landolfo KP, Clements F, et al. Mitral valve operation via Port Access versus median sternotomy. Eur J Cardiothorac Surg. 1998; 14(Suppl 1):S143-S147.

8. Mohr FW, Falk V, Diegeler A, Walther T, van Son JA, Autschbach R. Minimally invasive port-access mitral valve surgery. J Thorac Cardiovasc Surg. 1998;115:567-574.

9. Schwartz DS, Ribakove GH, Grossi EA, et al. Minimally invasive mitral valve replacement: port-access technique, feasibility, and myocardial functional preservation. J Thorac Cardiovasc Surg. 1997;113: $1022-1030$ 
10. Vanermen H, Vermeulen Y, Wellens F, De Geest R, Degrieck I, Van Praet F. Port-access mitral valve surgery. Perfusion. 1998;13:249-252.

11. Falk V, Cheng DC, Martin J, et al. Minimally invasive versus open mitral valve surgery: a consensus statement of the international society of minimally invasive coronary surgery (ISMICS) 2010. Innovations. 2011;6:66-76.

12. Holzhey DM, Shi W, Borger MA, et al. Minimally invasive versus sternotomy approach for mitral valve surgery in patients greater than 70 years old: a propensity-matched comparison. Ann Thorac Surg. 2011;91:401-405.

13. Luca F, van Garsse L, Rao CM, et al. Minimally invasive mitral valve surgery: a systematic review. Minim Invasive Surg. 2013;2013:179569.

14. Ritwick B, Chaudhuri K, Crouch G, Edwards JR, Worthington M, Stuklis RG. Minimally invasive mitral valve procedures: the current state. Minim Invasive Surg. 2013;2013:679276.

15. Svensson LG, Atik FA, Cosgrove DM, et al. Minimally invasive versus conventional mitral valve surgery: a propensity-matched comparison. $J$ Thorac Cardiovasc Surg. 2010;139:926-932.e1-2.

16. Vollroth M, Seeburger J, Garbade J, et al. Minimally invasive mitral valve surgery is a very safe procedure with very low rates of conversion to full sternotomy. Eur J Cardiothorac Surg. 2012;42:e13-e16.

17. Wolfe JA, Malaisrie SC, Farivar RS, et al. Minimally invasive mitral valve surgery II: surgical technique and postoperative management. Innovations. 2016;11:251-259.

18. Lehr EJ, Guy TS, Smith RL, et al. Minimally invasive mitral valve surgery III: training and robotic-assisted approaches. Innovations. 2016;11:260-267.

19. Youssef SJ, Millan JA, Youssef GM, Earnheart A, Lehr EJ, Barnhart GR. The role of computed tomography angiography in patients undergoing evaluation for minimally invasive cardiac surgery: an early program experience. Innovations. 2015;10:33-38.
20. Nishimura RA, Otto CM, Bonow RO, et al. 2014 AHA/ACC guideline for the management of patients with valvular heart disease: a report of the American College of Cardiology/American Heart Association Task Force on Practice Guidelines. J Am Coll Cardiol. 2014;63:e57-e185.

21. Kennedy JL, LaPar DJ, Kern JA, et al. Does the Society of Thoracic Surgeons risk score accurately predict operative mortality for patients with pulmonary hypertension? J Thorac Cardiovasc Surg. 2013;146:631-637.

22. Schachner T, Bonaros N, Bonatti J, Kolbitsch C. Near infrared spectroscopy for controlling the quality of distal leg perfusion in remote access cardiopulmonary bypass. Eur J Cardiothorac Surg. 2008;34:1253-1254.

23. Grossi EA, Loulmet DF, Schwartz CF, et al. Minimally invasive valve surgery with antegrade perfusion strategy is not associated with increased neurologic complications. Ann Thorac Surg. 2011;92:1346-1349.

24. Gammie JS, Zhao Y, Peterson ED, O'Brien SM, Rankin JS, Griffith BP. Less-invasive mitral valve operations: trends and outcomes from the Society of Thoracic Surgeons Adult Cardiac Surgery Database. Ann Thorac Surg. 2010;90:1401-1410.

25. Arcidi Jr JM, Rodriguez E, Elbeery JR, Nifong LW, Efird JT, Chitwood Jr WR. Fifteen-year experience with minimally invasive approach for reoperations involving the mitral valve. J Thorac Cardiovasc Surg. 2012;143:1062-1068.

26. Seeburger J, Borger MA, Falk V, et al. Minimally invasive mitral valve surgery after previous sternotomy: experience in 181 patients. Ann Thorac Surg. 2009;87:709-714.

27. Mazine A, Pellerin M, Lebon JS, Dionne PO, Jeanmart H, Bouchard D. Minimally invasive mitral valve surgery: influence of aortic clamping technique on early outcomes. Ann Thorac Surg. 2013;96:2116-2122.

28. Aybek T, Dogan S, Wimmer-Greinecker G, Westphal K, Mortiz A. The micro-mitral operation comparing the Port-Access technique and the transthoracic clamp technique. J Card Surg. 2000;15:76-81. 